\title{
APPLICATION OF THE INTERFEROMETER TO THE MEASUREMENT OF DIMENSIONAL CHANGES IN RUBBER
}

\author{
By Lawrence A. Wood, Norman Bekkedahl, and Chauncey G. Peters
}

\begin{abstract}
The interferometer method for the measurement of small dimensional changes is adapted here to measurements on soft rubber. A detailed description is given concerning the preparation of specimens, the apparatus, the procedure, and the calculations necessary for the application of this method. Particular emphasis is placed on the measurement of thermal expansivity and the dimensional changes involved in transitions between the different forms of rubber. The lower limit of temperature is set only by the refrigerating liquid, temperatures as low as $-185^{\circ} \mathrm{C}$ being utilized. The upper limit of temperature is set only by the rubber itself. Results obtained in a study of the expansivity and transitions of "stark" (frozen) rubber are given as an illustration of the application of the method. Other possible applications are the measurement of the swelling of rubber by vapors and the determination of stress-strain relations under compressive loads. The chief limitation of the application of this method to rubber arises from the plastic fiow of unvulcanized rubber at elevated temperatures. The method also possesses the inconvenience of requiring continuous observation. As compared with alternative methods of measuring small dimensional changes, the method possesses advantages arising from its high sensitivity, from the small size of the specimens required, from the ease of obtaining temperature equilibrium, from the absence of a confining liquid, and from the simplicity of the calculations.
\end{abstract}

\section{CONTENTS}

I. Introduction _...

II. Preparation of specimens

III. Apparatus

IV. Procedure

1. Placement of specimens

2. Elimination of errors arising from tilting

3. Elimination of moisture

4. Control of temperature

V. Calculations _._.

VI. Dimensional changes in stark rubber

VII. Advantages and limitations of the method

1. Dimensional measurements

2. Size and shape of specimens

3. Force on specimens

4. Plastic flow

5. Confining liquids

6. Temperature equilibrium

7. Calculations 


\section{INTRODUCTION}

The interferometer method for the measurement of small dimensional changes, previously used for many other materials, has been adapted in the present investigation to measurements on soft rubber. This method, which involves the counting of interference fringes of light of known wave length, was originated by Fizeau and developed by later workers. It has been most frequently applied to the measurement of thermal expansion. Merritt ${ }^{1}$ has described the principles and the procedure which have been commonly followed at this Bureau in measurements of thermal expansion by the interference method. Measurements have been made on metals, ${ }^{2}$ glass, ${ }^{3}$ and ceramic materials, ${ }^{4}$ especially at elevated temperatures.

The interference method has not been hitherto applied, however, as far as we are aware, to measurements on any of the various forms of rubber, with the single exception of ebonite, or hard rubber. ${ }^{5}$ The relatively easy deformation of most kinds of rubber gives rise to problems which do not occur in the application of the interferometer to most other materials. It is the purpose of this paper to discuss the apparatus used and the technique employed in the measurements of dimensional changes in rubber and to give consideration to the advantages and limitations of the method in its application to rubber. Particular emphasis is laid on measurements at temperatures as low as that of liquid air for the determination of the expansivity and of the dimensional changes and temperatures involved in transitions between the different forms of rubber. The method is not limited to measurements at different temperatures, however. It may be used in any case in which the measurement of dimensional changes is required. Possible applications of this sort are the measurement of the swelling of rubber by vapors and the determination of stress-strain relations under compressive loads.

\section{PREPARATION OF SPECIMENS}

The specimens, which were placed between the two interferometer plates, usually had a thickness of about 3 or $4 \mathrm{~mm}$. Two different types were utilized, the first a set of three small separate blocks ${ }^{6}$ a few millimeters on an edge, and the second a ring about $21 \mathrm{~mm}$ in outside diameter and about $15 \mathrm{~mm}$ in inside diameter.

The small blocks were cut out by a device consisting of two singleedged safety-razor blades fastened on a steel bar, which was mounted by means of a hinge arrangement on a wooden base. The spacing of the razor blades, which were parallel and about $3.5 \mathrm{~mm}$ apart, determined the thickness of the specimens and made these thicknesses very nearly the same. No particular effort was made to obtain uniformity in the other two dimensions. After a considerable number of specimens had been cut from the same sample, three of them were inserted between the interferometer plates, and substitutions of other

1 G. E. Merritt, The interference method of measuring thermal expansion, BS J. Research 10, 59 (1933) RP515. ${ }^{2}$ C. G. Peters and H. S. Boyd, Interference methods for standardizing and testing precision gage blocks, BS Sci. Pap. 1\%, 677 (1922) S436.

3 A. Q. Tool, D. B. Lloyd, and G. E. Merritt, Dimensional changes caused in glass by heating cycles, J. Am. Ceram. Soc. 13, 632 (1930); BS J. Research 5, 627 (1930) RP219.

$4 \mathrm{G}$. E. Merritt, Ap plication of the interferometer to measurements of thermal dilatation of ceramic materials. BS Sci. Pap. 19, 357 (1924) S485.

6 H. G. Dorsey, Linear expansion at low temperatures, Phys. Rev. 27, 1 (1908)

$6 \mathrm{C}$. G. Peters, The use of the interferometer in the measurement of small dilatations or differential dilatations, J. Wash. A cad. Sci. 9, 281 (1919). 
specimens were made, if necessary, until there were not more than 10 interference fringes visible across the face of the plate. In this manner, three blocks were selected which were of the same height to within a few wavelengths of light.

The ring specimens were cut with a die in an arbor press in the manner commonly used in the preparation of specimens for tensile tests. In this case, the height of the specimen, of course, was not changed by the cutting. Even from ribbed smoked sheet, it was found possible by cutting a large number of rings to select satisfactory specimens.

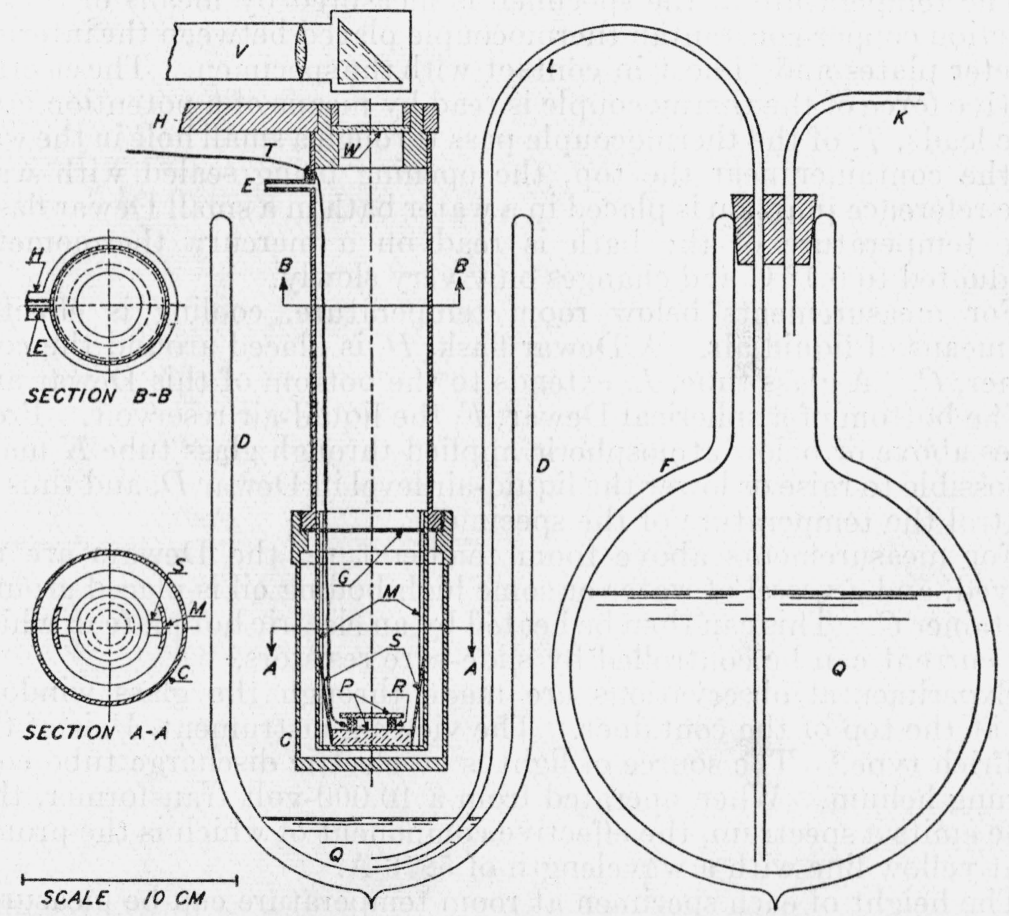

Frgure 1.-Cross section of the apparatus.

$C$, removable part of the container; $D$, Dewar flask; $E$, metal tube; $F$, spherical Dewar flask; $G$, leather gasket; $H$, arm supporting container; $K$, glass tube; $L$, glass tube; $M$, strips holding support for interferometer plates; $P$, interferometer plates; $Q$, liquid air; $R$, rubber specimen; $S$, flat steel springs holding lower interferometer plate in place; $T$, thermocouple leads; $V$, viewing instrument; $W$, window.

\section{APPARATUS}

A diagram of the major part of the apparatus is shown in figure 1 . It is essentially the same as that designed by Souder and Peters, ${ }^{7}$ with modifications for work at low temperatures. The rubber specimen, $R$, separates two interferometer plates of clear, transparent fused quartz, the surfaces of each of which have been polished optically flat. The surfaces of the upper plate are inclined to each other at an angle of about 20 minutes in order to separate the reflections of the images from the upper and lower surfaces. A finely ground surface on the

\footnotetext{
${ }^{7}$ W. Souder and O. G. Peters, An investigation of the physical properties of dental materials, Tech. Pap. BS $13(1920)$ T157.
} 
bottom of the lower plate avoids undesirable reflection from this surface. The upper plate used in most of this work was $2.65 \mathrm{~cm}$ (1.05 in.) in diameter, $0.635 \mathrm{~cm}(0.250$ in.) in thickness, and weighed $7.85 \mathrm{~g}$. The lower plate is held in position on its support by two flat steel springs, $S$, one on each side. The springs are fastened to the two strips, $M$, which hold the support.

A bar, $H$, the height of which is adjustable by means of a rack and pinion not shown, supports the whole assembly. A removable part, $C$, of the container can be screwed to the stationary part, the joint being made tight by means of a leather gasket, $G$.

The temperature of the specimen is measured by means of a twojunction copper-constantan thermocouple placed between the interferometer plates and almost in contact with the specimen. The electromotive force of the thermocouple is read by means of a potentiometer. The leads, $T$, of the thermocouple pass through a small hole in the wall of the container near the top, the opening being sealed with wax. The reference junction is placed in a water bath in a small Dewar flask. The temperature of the bath is read on a mercury thermometer graduated to $0.1^{\circ} \mathrm{C}$ and changes only very slowly.

For measurements below room temperature, cooling is effected by means of liquid air. A Dewar flask, $D$, is placed around the container, $C$. A glass tube, $L$, extends to the bottom of this Dewar and to the bottom of a spherical Dewar, $F$, the liquid-air reservoir. Pressures above or below atmospheric applied through glass tube $K$ make it possible to raise or lower the liquid-air level in Dewar $D$, and thus to control the temperature of the specimen.

For measurements above room temperature, the Dewars are removed, and a vessel of water or some high-boiling oil is placed around container $C$. This can then be heated by an electric hot plate in which the current can be controlled by slide-wire resistors.

Experimental observations are made through the glass window, $W$, at the top of the container. The viewing instrument, $V$, is of the Pulfrich type. ${ }^{8}$ The source of light is an electric discharge tube containing helium. When operated from a 10,000-volt transformer, this tube emits a spectrum, the effective component of which is the prominent yellow line with a wavelength of $5876 \mathrm{~A}$.

The height of each specimen at room temperature can be measured by means of some suitable instrument, such as the double-contact screw micrometer gage of the type designed earlier by Holt, ${ }^{9}$ who has since improved the design of the electric-contact indicator by the substitution of a small neon lamp operated from the 110-volt line. The height of the specimen is obtained in this manner as the difference of readings taken on the interferometer plates, first with the specimen in position for measurements and then with the plates in contact with each other.

\section{PROCEDURE}

The specimens must be placed in the apparatus in such a way as to make visible a relatively small number of interference fringes and to eliminate errors caused by the tilting of specimens. The condensation of moisture on various parts of the apparatus necessitates certain precautions as the temperature of the specimens is varied.

8 C. Pulfrich, The Abbe-Fizeau dilatometer, Z. Instrumentenk. 13, 365 (1893) 18, 261 (1898).

-W. L. Holt, Screw micrometer gages for rubber specimens, BS J. Research 10, 575 (1933) R P549. 


\section{PLACEMEN'T OF SPECIMENS}

It was found desirable that both types of specimens, before being placed in the interferometer, have their upper and lower surfaces lubricated with finely powdered graphite, such as Acheson No. 2301. After a liberal application of the graphite the surface was rubbed on a sheet of paper to remove the excess of the lubricant. Direct observation with the screw micrometer gage showed that there was no appreciable change of the measured thickness occasioned by this operation. Lubrication of the surface was necessary, as is explained below, in order to avoid difficulties caused by the dimensional changes in the rubber in directions parallel to the interferometer plates.

After three block specimens of nearly equal height had been selected and lubricated as described, they were placed between the interferometer plates, near the edge of the upper plate and equidistant from each other. Next it was necessary to determine which of the specimens had the greatest height. This could be accomplished by pushing down gently on the center of the top interferometer plate, and noting the direction of motion of the fringes which is necessarily toward the point of greatest thickness.

The highest specimen was next moved toward the center of the plates, so that the load supported by that block could be increased from about one-third the weight of the upper plate to any desired value up to nearly the whole weight of the plate. The increased load on the highest block decreased the number of visible interference fringes, making the blocks, through the increased load, more nearly equal in height. Adjustment was made in this manner until not more than six or seven fringes appeared in the field of view.

It was next necessary to locate the point of contact carrying the greatest load. After a gentle tapping of the container supporting the plates, the interference fringe passing through the point of contact would remain stationary, while the other fringes would vibrate for a brief interval. The viewing instrument then was adjusted so that its cross hairs coincided with the point of contact.

A procedure essentially similar was followed when ring specimens were employed. Pressure applied on the top of the upper plate indicated which part of the specimen was highest. The ring was then moved so as to bring the high part closer to the center of the upper plate. The remainder of the procedure was the same as with the block specimens.

\section{ELIMINATION OF ERRORS ARISING FROM TILTING}

This method of making observations at the point of greatest load on the block specimens was suggested by J. B. Saunders, of this Bureau, who has recently discussed ${ }^{10}$ the matter with particular reference to glass specimens. The method eliminated difficulties arising from the tilting of block specimens. Because of the difference in thermal expansivity between the specimens and the interferometer plates, there must be some relative motion of the surfaces of specimens and plates as the temperature is varied. If the surfaces are well lubricated, as by the use of graphite in the present work, this motion can take place as uniform slippage. If, however, there is sticking in

$10 \mathrm{~J}$. B. Saunders, Improved interferometric procedure with application to expansion measurements, J. Research NBS 23, 179 (1939) RP1227. 
at least two specimens at points which are not immediately above each other, tilting of the specimens must occur, with consequent changes in the distance between interferometer plates. Such changes, of course, lead to false values for the expansivity, since the effective height of the specimen varies with the angle of tilt. An analysis of the stability of the system shows that a decrease in the angle of tilt at the specimen which is most heavily loaded, with consequently increased angles of tilt at the other specimens, results in a lowering of the center of gravity of the upper plate. Therefore, in actual practice all the tilting will occur at the lightly loaded specimens, and measurements at the point of contact of the most heavily loaded specimen will free the data from this error. Tilting of the lightly loaded specimens gives rise to a tilting of the upper interferometer plate. Such tilting, when it occurs, is evidenced by a change in the width of the interference fringes and consequently in the number of fringes visible. Thermal expansion alone causes a change in the width of the fringes of only the same percentage as the expansion itself. Since the expansion amounts to less than 3 percent over the whole range of temperature studied in the present work, and since changes of this amount in the width of the bands are almost unobservable, appreciable changes in the number of visible interference fringes may be ascribed entirely to sticking of the surfaces with consequent tilting.

Sticking of the surfaces of the ring and interferometer plates gives rise to deformations producing changes in the effective height of the ring, in a manner similar to the tilting of the block specimens. In this case, however, false values of the expansivity cannot be avoided by taking observations at the point of heaviest loading. It is, therefore, essential with ring specimens to avoid all sticking by the liberal application of lubricant. In some cases a tapping of the container was found necessary to bring about slippage.

\section{ELIMINATION OF MOISTURE}

Since the presence of moisture inside the apparatus gives rise to difficulties, the container should be closed tightly. The removable part, $C$, was consequently brought up around the specimens and screwed tightly in place. It was necessary, of course, during this process to avoid severe jolts, which might disturb the interference fringes. The joint was next wrapped with several turns of rubber tape, so that any water formed by condensation on the outside of the container might run down past the joint and not penetrate the leather gasket. The container was next evacuated through tube $E$ and then filled with air which had been dried by passage over calcium chloride. If this were not done and if, consequently, water vapor in appreciable quantity were present inside the container, condensation would occur on the interferometer plates during warming from the lower temperatures, since the plates are then colder than the metal parts on which the vapor condenses during cooling. The presence of small amounts of condensed vapor on the plates can be tolerated, but beyond a certain limit light is no longer regularly reflected from the surfaces of the plates, and the field of view becomes dark. 
If the humidity of the atmosphere was at all high, condensed moisture collected on the top surface of window $W$, when the container was kept at the lowest temperature. As a temporary expedient, the moisture was wiped off with a bit of absorbent cotton whenever present in sufficient quantities to interfere with vision; but it was found to be much more satisfactory to reduce the humidity of the room by an appropriate air-conditioning unit.

\section{CONTROL OF TEMPERATURE}

For measurements below room temperature, liquid air was used as the cooling medium. An atomizer bulb of rubber was placed on tube $K$ and used to force the liquid air from the spherical Dewar, $F$, through tube $L$ into Dewar $D$. By careful control of the level in $D$, the rate of cooling or warming of the specimen could be kept less than $1^{\circ} \mathrm{C}$ per minute, a value which it was found desirable not to exceed. The fringes passing the cross hairs were counted during both cooling and warming. The temperature was observed at the passage of every fifth fringe and on some occasions more frequently. The time also was recorded so that the rate of cooling or heating could be known. The temperature of the specimen, when the liquid-air level was brought to within a few inches of the top of Dewar $D$, became very nearly that of the liquid air, values lower than $-180^{\circ} \mathrm{C}$ being always obtained after thermal equilibrium. After the minimum temperature had been attained, a considerable portion of the liquid air was removed from Dewar $D$ by reducing the pressure in Dewar $F$ by means of a pump connected to tube $K$. In this manner, the temperature of the specimen was allowed to rise at a controlled rate.

Before beginning observations at elevated temperatures, the bath of water or oil was cooled about 10 or 20 degrees below room temperature, and the current in the hot plate adjusted to a convenient value. It was found desirable to make as few changes in the heating current as possible, ranges of at least $20^{\circ}$ or $30^{\circ}$ being covered without change of the current. The rate of temperature rise decreased, of course, over each range. Preliminary runs were used to determine the value of the heating current for each range so that the initial rate of temperature rise should not exceed about $1^{\circ} \mathrm{C}$ per minute and that the final rate should not be unduly small.

\section{CALCULATIONS}

The essential data obtained during a run consist of the number of fringes which have passed the cross hairs, the corresponding voltage of the thermocouple, and the temperature of the fixed junction. From these one can calculate the change in length of the specimen and its temperature. Since the light traverses the space between interferometer plates twice, the vertical displacement of the upper plate when one fringe has passed the cross hairs is equal to one-half the wavelength. The change in length of the specimen between room temperature and any other temperature is obtained, therefore, by multiplying the number of fringes which have passed the cross hairs by one-half the wavelength. At room temperature the effective wavelength of the light used is $0.5876 \mu$. At other temperatures the wavelength is different because of the variation of the refractive 
index of air with temperature. A table of corrections to take account ${ }^{11}$ of this fact and the method of application are found in the paper by Merritt. ${ }^{12}$

The temperatures were read from a large calibration graph, which had been prepared from the standard tables for copper-constantan thermocouples given in the International Critical Tables. ${ }^{13}$ The procedure described there was followed, a comparison between the thermocouple and a standard thermocouple being made at the temperature of liquid air.

A few selected lines of typical data and calculated results are shown in table 1 to illustrate the method usually followed. Columns $1,2,6$, and 7 contain the quantities directly observed. The fourth column, "Air correction," contains values taken from Merritt's tables, for the correction for the change of refractive index of air with temperature. The seventh column gives the temperature of the fixed junction as read on the mercury thermometer. The next column gives the corresponding electromotive force obtained from the calibration curve of the thermocouple. The sum of this value and the potentiometer reading yields the potentiometer reading which would have been obtained had the fixed junction been held at $0^{\circ} \mathrm{C}$, and this sum is shown in the ninth column.

TABLE 1.-Typical data and calculations

Original height of specimen, $l_{20}=0.372 \mathrm{~cm}$.

Wave length of helium line, $\lambda=0.5876 \mu$.

Value of $\frac{\lambda}{2 l_{20}}=0.790 \mu / \mathrm{cm}$.

\begin{tabular}{|c|c|c|c|c|c|c|c|c|c|}
\hline Time & $\begin{array}{c}N \text { fringe } \\
\text { number }\end{array}$ & $0.790 N$ & $\begin{array}{c}\text { Air cor- } \\
\text { rection }\end{array}$ & $\begin{array}{c}\Delta L_{1} \text { ex- } \\
\text { pansion }\end{array}$ & $\begin{array}{c}\text { Potenti- } \\
\text { ometer } \\
\text { reading }\end{array}$ & $\begin{array}{c}\text { Temper- } \\
\text { ature of } \\
\text { fixed } \\
\text { junction }\end{array}$ & $\begin{array}{c}\text { Fixed } \\
\text { junc- } \\
\text { tion } \\
\text { electro- } \\
\text { motive } \\
\text { force }\end{array}$ & $\begin{array}{c}\text { Thermo- } \\
\text { couple } \\
\text { corrected } \\
\text { electro- } \\
\text { motive } \\
\text { force }\end{array}$ & $\begin{array}{c}\text { Tempera } \\
\text { ture }\end{array}$ \\
\hline & & $\mu / c m$ & $\mu / c m$ & $\mu / c m$ & $\mu V$ & $\circ C$ & $\mu V$ & $\mu V$ & $\circ C$ \\
$9: 00$ & -35 & -27.6 & 0.1 & -27.5 & $-1,310$ & 23.6 & 1,900 & 590 & 7.4 \\
$9: 02$ & -40 & -31.6 & .1 & -31.5 & $-1,460$ & 23.6 & 1,900 & 440 & 5.6 \\
\hline $11: 41$ & -283 & -223.5 & 5.8 & -217.7 & $-12,620$ & 24.5 & 1,980 & $-10,640$ & -180.2 \\
$11: 48$ & -283.7 & -224.0 & 5.9 & -218.1 & $-12,640$ & 24.6 & 1,990 & $-10,650$ & -180.5 \\
\hline
\end{tabular}

$1 N$ is the number of fringes which have passed the reference point, the negative value indicating contraction of the specimen.

\section{DIMENSIONAL CHANGES IN STARK RUBBER}

The results obtained in a study of frozen rubber illustrate the type of work which can be done by this method. The form of frozen rubber investigated had a melting point above room temperature and has been called stark rubber by Pickles ${ }^{14}$ and by Whitby. ${ }^{15}$

The change in dimensions resulting from the melting of a specimen of stark rubber is shown in figure 2. The sample, for which we are

11 C. G. Peters and C. S. Cragoe, Thermal dilatation of glass at high temperatures, BS Sci. Pap. 16, 449 (1920) S393.

${ }_{12} \mathrm{G}$. E. Merritt, The interference method of measuring thermal expansion, BS J. Research 10, 59 (1933) RP515.

${ }_{13}^{13}$ L. H. Adams, Int. Crit. Tables 1, 58. (McGraw-Hill Book Co., Inc., New York, N. Y., 1926).

$14 \mathrm{~S}$. S. Pickles, The consistency of rubber and rubber compounds, India Rubber J. 67, 69 (1924).

15 G. S. Whitby, chapter 2, Physical Properties of Raw Rubber, in Davis and Blake: Chemistry and Technology of Rubber, p. 102 (Reinhold Publishing Corporation, New York, N. Y., 1937). 
indebted to H. I. Cramer, of the University of Akron, had been in the frozen state for less than a year. The initial heating rate was approximately $0.4^{\circ} \mathrm{C}$ per minute and decreased to about $0.16^{\circ} \mathrm{C}$ per minute at the highest temperature. At this point the heating bath was removed and the specimen allowed to cool. The temperature decreased at an initial rate of about $0.95^{\circ} \mathrm{C}$ per minute, and the rate diminished to less than $0.1^{\circ} \mathrm{C}$ per minute at the last observation.

The difference in ordinates of the heating and cooling curves at $25^{\circ} \mathrm{C}$ represents the difference in heights of the amorphous and the crystalline forms. It can be read from the graph as $91.5 \mu / \mathrm{cm}$. Assuming the specimen isotropic, one finds that this corresponds to a volume increase of 2.77 percent, a value not very different from those found ${ }^{16}$ at $0^{\circ} \mathrm{C}$ for rubber which melted near $11^{\circ} \mathrm{C}$. The general form of the graph is typical of the melting curve of rubber, but linear expansivities calculated from the slopes in figure 2 are abnormally high, probably because the specimens were not lubricated during this

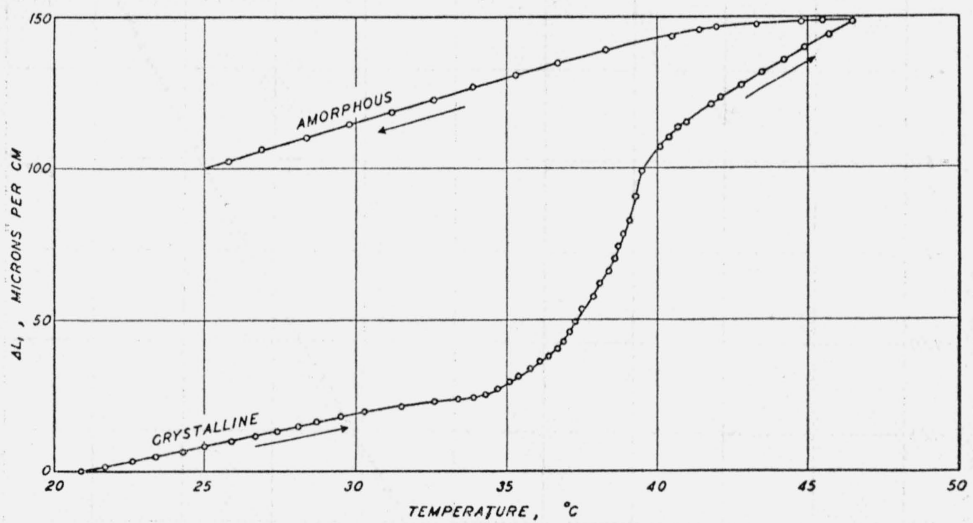

Figure 2.-Dimensional changes during the melting of stark rubber.

particular run. The importance of lubrication was not appreciated at the time of this measurement.

The results of measurements of the dimensional changes in a different sample of stark rubber over a large range of temperatures are shown in figure 3 . We are indebted to G. S. Whitby for furnishing the sample, which had been in the frozen state for 25 years (from 1913 to 1938 ).

The specimens were cooled from room temperature to that of liquid air. They were allowed to warm up nearly to room temperature, and electric heating was then applied. The melting range in this case began at about $40^{\circ} \mathrm{C}$, but observations could not be continued above $43^{\circ} \mathrm{C}$, because at this point permanent deformation of the specimens under the weight of the upper plate occurred.

In figure 3 the circles represent experimental points obtained when the temperature was changing at a rate of less than $1^{\circ} \mathrm{C}$ per minute. Under these conditions it is thought that the difference between the actual effective temperature of the specimens and that indicated by

${ }_{10} \mathrm{~N}$. Bekkedahl, Forms of rubber as indicated by temperature-volume relationship, J. Research NBS 13, 411 (1934) RP717. 
the thermocouple is negligible. This is shown by the good agreement between the values obtained as the temperature was increasing (dark circles) and the values obtained as the temperature was decreasing (open circles). Observations made when the temperature was changing at a rate greater than $1^{\circ} \mathrm{C}$ per minute are shown as dots. Under these conditions a difference between values obtained with increasing and decreasing temperatures can be seen.

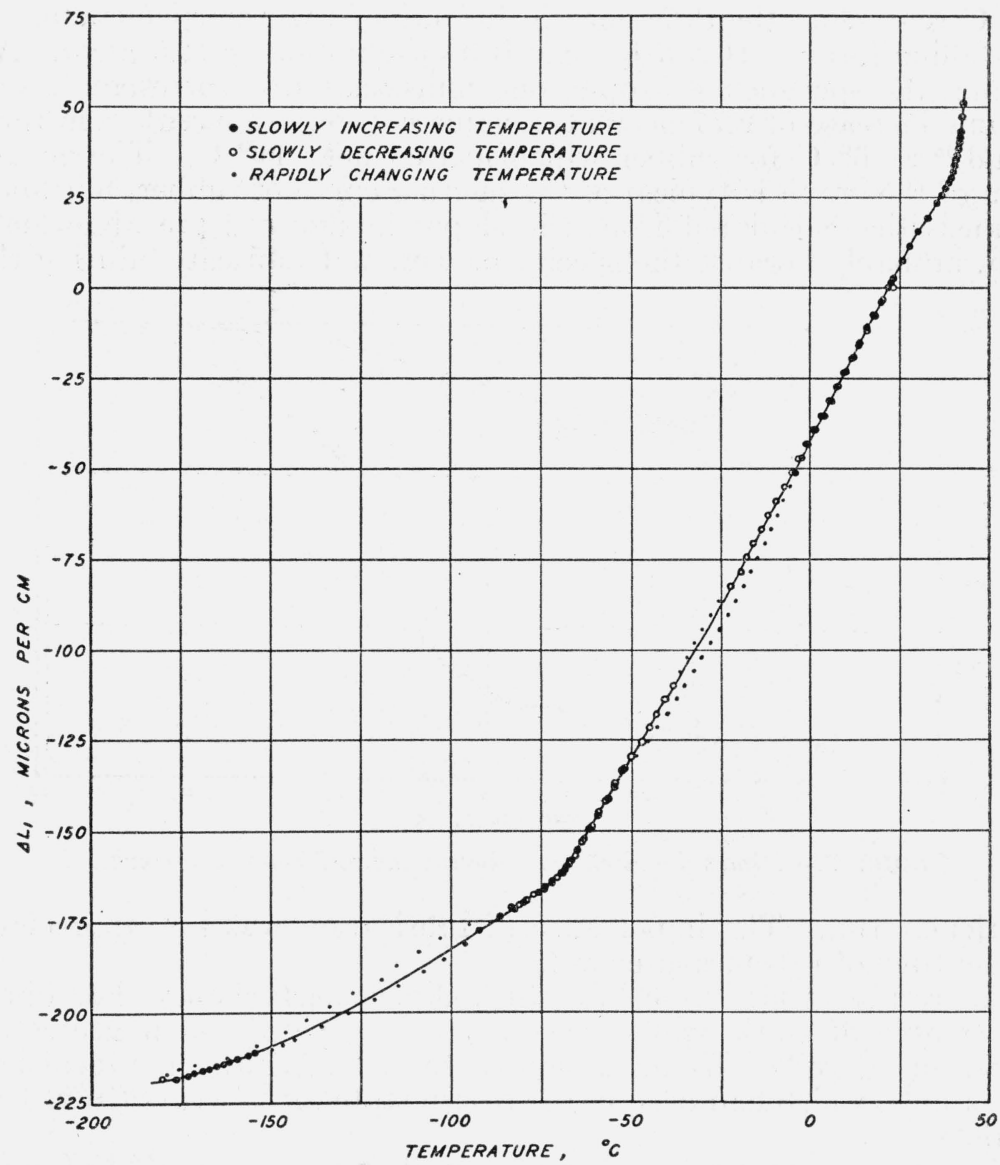

FigURE 3.-Dimensional changes in stark rubber.

The same data in the interesting region from $-54^{\circ}$ to $-84^{\circ} \mathrm{C}$ have been plotted on a much larger scale in figure 4 to show the transition ${ }^{17}$ of the second order near $-70^{\circ} \mathrm{C}$. The linear expansivity from $-71^{\circ}$ to $-84^{\circ} \mathrm{C}$ is read from the graph as $77 \times 10^{-6}$ per degree, while the linear expansivity from $-67^{\circ}$ to $-54^{\circ} \mathrm{C}$ is found to be $175 \times 10^{-6}$ per degree. These ranges of temperatures are, of course, insufficient to show the continuous variation of expansivity with temperature. The variation is evident over the larger ranges shown in figure 3.

${ }_{17} \mathrm{~N}$. Bekkedahl, Forms of rubber as indicated by temperature-volume relationship, J. Research NBS 13, 411 (1934) RP717. 


\section{ADVANTAGES AND LIMITATIONS OF THE METHOD}

The interference method of measuring dimensional changes in rubber possesses certain advantages as compared with other methods, and, of course, certain attendant disadvantages. There are, in addition, certain limitations which restrict its use. The advantages and limitations will now be compared with those of the chief alternative methods.

\section{DIMENSIONAL MEASUREMENTS}

If there is reason to think that the rubber specimens are not isotropic, some method, such as the interference method, by which one can measure separately the three linear dimensional changes, is required. Any method involving merely the measurement of volume changes would give insufficiently detailed information about the changes in different directions.

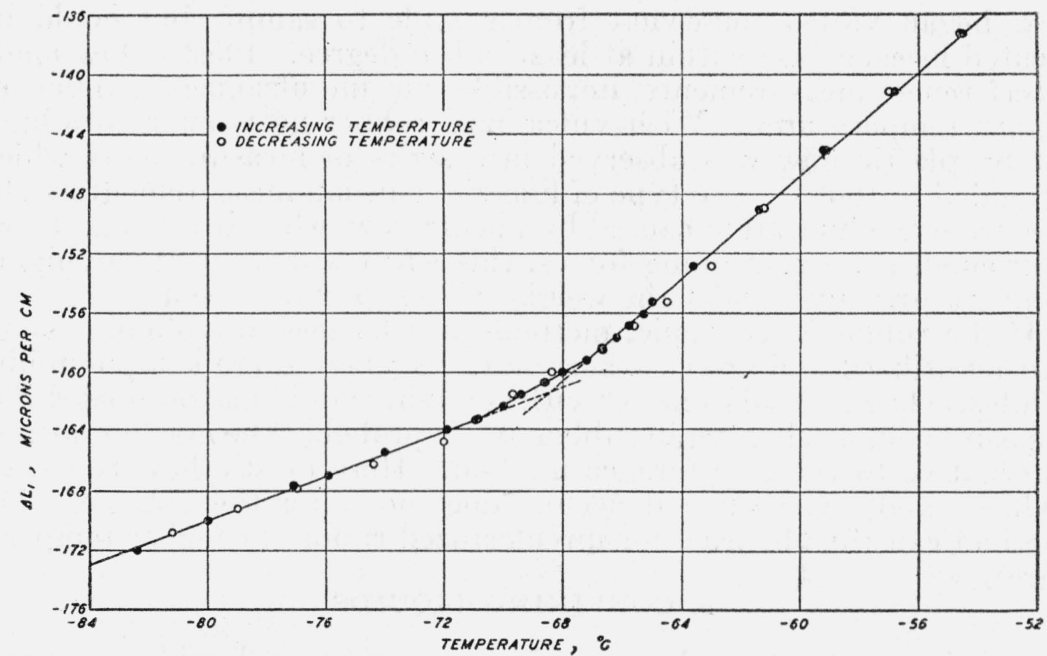

FIgURe 4.-Dimensional changes in stark rubber passing through a second-order transition.

This is a part of figure 3 shown on a larger scale.

\section{SIZE AND SHAPE OF SPECIMENS}

The interference method has been found more satisfactory for rubber than other familiar methods for linear measurements, which require a specimen in the form of a rod and which measure expansions by means of a dial gage,$^{18}{ }^{19}$ optical lever, or similar arrangement.

The interferometer specimens are very small and can easily be cut to shape. In spite of the small size of the specimens, the sensitivity of the method is quite great, since measurements of changes of length are made by comparison with the wave length of light. In the other methods the specimens need to be much larger and must be formed or molded to a particular shape.

${ }_{18}$ P. Hidnert and W. T. Sweeney, Thermal expansion of magnesium and some of its alloys, BS J. Research 1, 771 (1928) RP29.

${ }_{10} \mathrm{~N}$. Bekkedahl, Forms of rubber as indicated by temperature-volume relationship, J. Research NBS 13, 411 (1934) RP717. 


\section{FORCE ON SPECIMENS}

Most of the methods used for linear measurements exert some constraint on the rubber, either from the measuring mechanism or from the means of support. In the case of the interference method, the lateral constraint from the support is made quite small by the lubrication with graphite, but the vertical constraining force on the specimen due to the weight of the upper interferometer plate is, of course, of appreciable magnitude. This force is constant for a given plate and is of known size. Moreover, by the use of different plates, the force may be altered. Satisfactory plates weighing considerably less than $1 \mathrm{~g}$ can be made.

\section{PLASTIC FLOW}

Plastic flow of the unvulcanized rubber was not observed at the lower temperatures and did not occur until temperatures somewhat above $40^{\circ} \mathrm{C}$ were reached. The temperatures at which the plastic flow began varied somewhat from sample to sample but could be located in each case within at least half a degree. Plastic flow made interference measurements impossible on unvulcanized rubber at higher temperatures. With vulcanized rubber no temperature limit set by plastic flow was observed in a series of measurements which extended to $100^{\circ} \mathrm{C}$. No type of linear-expansion measurement can be free from the limitation caused by plastic flow, when it occurs. However small the constraining forces, this effect will occur at the higher temperatures even under the weight of the specimen itself.

If the rubber is isotropic, methods which measure volume change can be utilized and are necessary in cases where there is a possibility of plastic flow. A dilatometer with confining liquid has been used ${ }^{20}$ to measure volume changes in rubber and is probably the most important alternative to the interference method. Here plastic flow is greatly reduced and, even when it occurs, does not alter the volume. The method can thus be used for unvulcanized rubber at higher temperatures.

\section{CONFINING LIQUIDS}

The interference method requires no confining liquid in contact with the rubber and is free from difficulties arising from the presence of the confining liquid usually necessary in a volume dilatometer.

None of the common liquids which are thought to be without swelling action on rubber remain liquid much below $-100^{\circ} \mathrm{C}$, and, in actual practice, work using a confining liquid has been limited to the range above $-85^{\circ} \mathrm{C}$ because of the excessive viscosity of those liquids which do not actually crystallize above $-100^{\circ} \mathrm{C}$. The interference method is free from this temperature limitation, and measurements have been continued to temperatures as low as that of liquid air. With certain modifications of technique, the temperatures might be carried still lower to limits set only by the refrigerating liquid.

Furthermore, it has not been established that the presence of a confining liquid, even one which does not swell rubber appreciably, is completely without influence on the occurrence of transitions. For example, there seems to be evidence ${ }^{20}$ that the presence of acetone

${ }^{20} \mathrm{~N}$. Bekkedahl, Forms of rubber as indicated by temperature-volume relationship, J. Research NBS 13, 411 (1934) RP717. 
inhibits the second-order transition normally occurring near $-70^{\circ} \mathrm{C}$, or at least lowers the temperature at which it occurs.

Other disadvantages of a confining liquid are the constant possibility of evaporation during a run, and the difficulties caused by the liberation of dissolved gases, as the temperature is raised. Usually, if a fair degree of sensitivity is required, ranges of not more than $30^{\circ}$ or $40^{\circ} \mathrm{C}$ can be covered without the addition or removal of liquid.

\section{TEMPERATURE EQUILIBRIUM}

In comparison with other methods for either linear measurements or volume measurements, the specimens used in the interferometer are quite small. Therefore, in addition to the resultant economy of material, there is the advantage that the attainment of temperature equilibrium throughout the rubber is relatively rapid. Consequently, changes of temperature can safely be made much more rapidly than in cases where large specimens are used, when the attainment of equilibrium is delayed by the relatively poor thermal conductivity of rubber. The expansivity over the range of temperatures from that of liquid air to room temperature can therefore be measured by the interference method in a single working day. With some of the other methods, observations must extend over several days. For dimensional changes of such nature as to require more than 1 day for completion, such as might occur during swelling and freezing, the interference method is not so convenient, since it requires continuous observation.

This inconvenience might be removed by adopting photographic recording ${ }^{21}$ or a different interference method involving the use of a block of fixed height and the counting of the number of interference fringes between two marks rather than the counting of the number of fringes which pass a given mark.

Because of the relatively rapid attainment of temperature equilibrium in the interference method, it is convenient to carry out measurements with decreasing temperatures as well as with increasing temperatures. Thus, any permanent distortion is immediately obvious.

\section{Calculations}

The calculation of expansivities from interference measurements is considerably simpler than from volume measurements. In the latter case, for example, it is necessary to take account of the expansion of the glass bulb and of the confining liquid, as well as to make corrections for the temperature of the exposed stem. The different amounts of confining liquid necessary for different temperature ranges further complicate the calculations.

The interference method introduces no discontinuous intervals of temperature into the calculations. As shown by figures 2 and 4 , it can give results of considerable detail in studies of the nature of a transition.

Washington, September 1, 1939.

${ }^{21}$ F. C. Nix, A vacuum interferometric dilatometer with photographic recording, Phys. Rev. 55, 606A (1939): 